\title{
DEVELOPMENT OF TECHNOLOGY OF CREAMS USING HYDROCOLLOIDS
}

\author{
Svitlana Andrieieva ${ }^{1} \bowtie$ \\ svetana783@ukr.net \\ Aliona Dikhtyar \\ Olga Grinchenko ${ }^{1}$ \\ Yevgen Pyvovarov ${ }^{l}$ \\ Maryna Kolesnikova ${ }^{1}$ \\ Svitlana Omel'chenko ${ }^{1}$ \\ Oleg Kotlyar ${ }^{1}$ \\ ${ }^{1}$ Department of Food Technology in the Restaurant Industry \\ State Biotechnological University \\ 44, Alchevskikh str., Kharkiv, Ukraine, 61000
}

$\triangle$ Corresponding author

\begin{abstract}
The article presents a scientific study of the functional and technological properties of hydrocolloids, namely thickeners of polysaccharide nature, which are used as thickeners and stabilizers in dessert products. According to the monitoring of literature sources and the experience of manufacturers, the most commonly used thickeners of polysaccharide nature are carrageenan, locust bean gum, xanthan gum, pectin, starch, etc. However, each of these polysaccharides has both positive and negative sides, more polysaccharides are able to form dense gels, but with a high synergistic effect. Thickeners, such as $k$-carrageenan, low-esterified pectins, can form gels only in the presence of $\mathrm{Ca}^{2+}$. There are also polysaccharides that form gels only at low temperatures and are not stable during external factors (temperature of sale and storage, mechanical impact, etc.).

Therefore, the study was conducted on the combination of polysaccharides in order to obtain creams with an airy gel-like structure. It has been determined, that it is expedient to use the combination "xanthan gum $0.75 \%$ - locust bean gum $0.5 \%$ " to obtain cream.

Keywords: polysaccharides, carrageenan, locust bean gum, xanthan gum, cream
\end{abstract}

DOI: $10.21303 / 2504-5695.2021 .002187$

\section{Introduction}

An important aspect in the development of creams based on raw milk is the use of available, multifunctional raw materials. It determines the interest in studying the possibility of using substances of polysaccharide nature, in particular, such as agar, carrageenans, pectins and gels of animal origin - gelatin, in creams.

Despite the extensive experience of using structurants in food systems, for creams there is a need to justify the choice of structurants, because cream as a technological environment is characterized by a set of technological properties that affect the structure $[1,2]$.

Creams are an emulsion product, so manufacturers often use gelatin. Because gelatin molecules contain hydrophobic and hydrophilic moieties, they are able to concentrate on the phase interface, for example, in oil-water or air-water systems, reducing surface tension. In such two-phase systems, individual foam bubbles or emulsion droplets are surrounded by a gelatin gel film. This film is stable and resistant to mechanical influences, as a result of which the dispersed phase does not coalesce in the dispersion medium, thereby protecting the foam or emulsion from destruction [3]. 
In addition to the prescription composition of the cream and the method of foaming, the foaming process and the stability of the obtained foams can be influenced by the following factors: $\mathrm{pH}$ of raw materials, in particular fruit and berry as a filler, gelation temperature, gelatin type, dispersed phase ratio and dispersed medium. According to sources [4] in dairy systems carrageenans show a high thickening and gelling ability due to the emergence of calcium bridges between molecules of $k$-casein and carrageenan. Since the interaction of k-carrageenan with $k$-casein during cooling significantly strengthens the network of double helices, a much lower concentration of polysaccharide is required for gelation of the dairy system than water (approximately 5 times). Molecules of $\lambda$-carrageenan are also able to interact with milk proteins - the viscosity of milk with a content of $0.05-1.0 \%$ of carrageenan corresponds to its viscosity of aqueous solutions with a concentration of $0.5-1.0 \%$ [4-6].

$K$-carrageenan is often included in dairy systems as a secondary stabilizer in a concentration of $0.01-0.015 \%$, which does not lead to their gelation. The concentration gel point of $k$-carrageenan in milk is about $0.2 \%$, in water $-0.5 \%, i$-carrageenan $-1.5 \%$ in milk and $2.0 \%$ in water [7].

Mixtures of $i$ - and $k$-carrageenan are widely used in the technology of desserts with a gellike structure, due to their high melting point, stable structural and mechanical properties of gels during storage and low syneresis. When $k$-carrageenan and xanthan are used together, synergism is manifested in a significant increase in the viscosity of liquid and elastic gel-like systems. Whipped desserts, made from a combination of carrageenan and pectin, are characterized by a stable texture for a long time and, unlike gelatin, resistance to the freezing process $[8,9]$.

Locust bean gum is dispersed in water, milk, salt and sugar solutions. Locust bean gum dissolves in hot water, and such a solution reaches the highest viscosity at temperatures above $80{ }^{\circ} \mathrm{C}$. Gum solutions are stable at $\mathrm{pH}$ 4.5-10.0. In food systems, locust bean gum has a creamy texture. In "cold" technological processes, locust bean gum shows a thickening ability, but at high temperatures the effect of the presence of polysaccharide in the system is reduced [10].

When used in combination with other gums, in particular with xanthan and carrageenan, locust bean gum has a strong synergistic effect, which facilitates gelation and increases the strength of the gel, allows to obtain a stable product quality and a given economic effect.

Xanthan gum solutions have excellent stability at low $\mathrm{pH}$ values over a long period of time. At a normal temperature of $20^{\circ} \mathrm{C}$, the viscosity of xanthan gum remains stable for several weeks in the presence of acid [11].

Functional mixtures of xanthan gum, carrageenan, locust bean gum are effective stabilizers for a number of dessert products, especially for creams, mousses, souffles. Therefore, the following studies were conducted to determine the rational combination of polysaccharides.

The aim of the study is to substantiate the technology of cream using a combination of polysaccharides.

To achieve this aim, it is necessary to solve the following tasks:

- to substantiate the types of hydrocolloids and their principles of combination in the technology of cream;

- to investigate the structural and mechanical properties of the combination of polysaccharides under the influence of technological factors (sugar content, shelf life);

- to investigate the foaming ability of model systems based on dairy and fruit and berry raw materials depending on the concentration of hydrocolloid;

- to determine the organoleptic characteristics of the developed desserts.

\section{Materials and methods}

Solutions of gelatin, agar, low-esterified pectin were prepared by dispersing a dry portion of powder in water or milk at a temperature of $80 \ldots 85^{\circ} \mathrm{C}$, followed by heating to a temperature of $98 \ldots 100{ }^{\circ} \mathrm{C}$ and keeping for $2 \ldots 2.5$ hours

Solutions of $k$-carrageenan, xanthan gum (XG), locust bean gum (LBG) were prepared by dispersing a dry portion of powder in water at a temperature of $20 \ldots 25^{\circ} \mathrm{C}$ and keeping for $20 \ldots 30$ minutes at a temperature of $80 \ldots 85^{\circ} \mathrm{C}$ for complete dissolution of dry matter. 
Model systems (MS) "cream - drinking water - hydrocolloid" were prepared by mixing pre-filtered cream with drinking water. The hydrocolloids were dispersed in cream at a temperature of $80 \ldots 85^{\circ} \mathrm{C}$, followed by heating to a temperature of $98 \ldots 100{ }^{\circ} \mathrm{C}$ and keeping for $(2.0 \ldots 2.5) \times 60^{2} \mathrm{~s}$.

Also used other raw materials: chicken eggs according to DSTU 5028: 2008, baked milk according to DSTU 2661-94, instant coffee "Jacobs Monarch" according to the relevant regulations, fruit and berry puree "Wild berries" LLC "Agrono-fruit" (Ukraine, Vinnytsia) according to the relevant regulations.

Structural and mechanical properties of model systems based on hydrocolloids (modulus of elasticity) were determined using modified Kargin-Sologova scales by studying the compression deformation of structured systems under the action of a load at constant stress. Mathematical and statistical processing of the results of rheological studies was carried out using the software package Microsoft Excel [12].

The active acidity of fruit and berry puree "Wild berries" was determined using an ionomer I 130 (Belarus, Gomel) with an electrode system for pH measurement [12].

The foaming ability of prescription mixtures was determined by the formula [12]:

$$
F A=\frac{V_{f}}{V_{p}} \cdot 100,
$$

where $F A$ - foaming ability, $\% ; V_{f}$ - volume of the foam, $\mathrm{m}^{3} ; V_{p}$ - volume of the sample before shaking, $\mathrm{m}^{3}$.

The stability of the foam of the prescription mixtures was determined by the formula:

$$
F S=\frac{B_{f}^{15}}{B_{f}} \cdot 100,
$$

where FS - foam stability, $\% ; B_{f}^{15}$ - height of the foam after $(15 \bullet 60)$ s keeping; $B_{n}$ - initial height of the foam, m.

\section{Results}

The gelation process is, to some extent, a controlled one. In this regard, it is necessary to study in more detail the combinations of polysaccharides and the influence of various factors on the gelling ability of polysaccharides (Fig. 1).

To determine the regularities of stability of model systems based on cream and hydrocolloids, the strengths based on milk and hydrocolloids were investigated.

Model systems have been developed for experimental research, the main ones being drinking cream and skim cow's milk. Polysaccharide compositions with appropriate concentrations were selected as gelling agents. To compare the structural and mechanical characteristics of MS, the classic technology of cream production using gelatin at a concentration of $2.0 \%$ was chosen as a control (Table 1, Fig. 2-6).

Determining the effect of thermodynamically compatible polysaccharides on the strength of gels proved that the introduction of locust bean gum to MS-1 and for MS-3 increases the strength of gels 1.7 times from the control sample with gelatin, and 1.2 times for MS-2, containing agar. It has been found, that the combination of low-esterified pectin with $k$-carrageenan forms strong (dense) gels.

In the process of obtaining a multicomponent recipe mixture, the cream before introduction into the milk-egg mixture is whipped to obtain a foamy mass. Therefore, the next stage of this study was to study the effect of combined polysaccharides on the foaming ability (FA) and foam stability (FS) of model systems (Table 2).

As can be seen, one of the influential compositions of polysaccharides is a mixture of $k$-carrageenan and LP, as well as a mixture of XG and LBG, the data show complete stability of the foams for 40 minutes. 


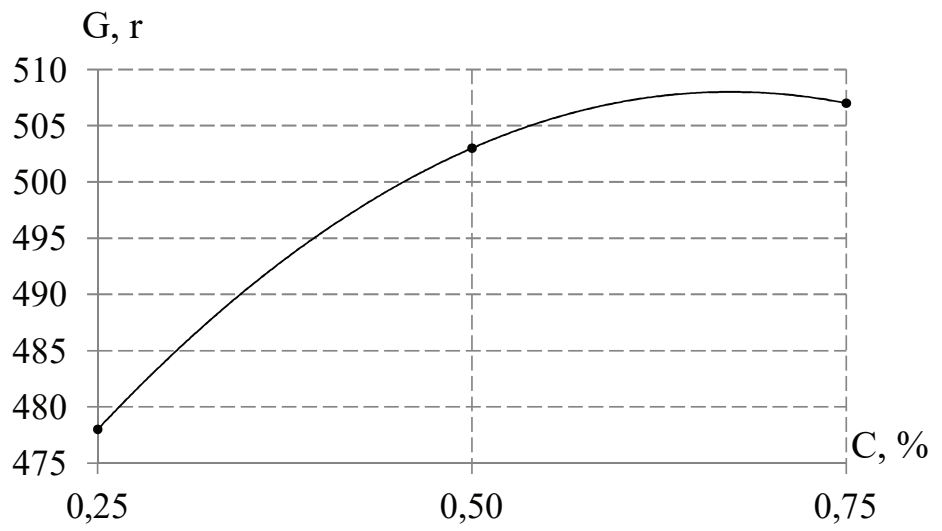

Fig. 2. Dependence of the strength of MS-1 gels

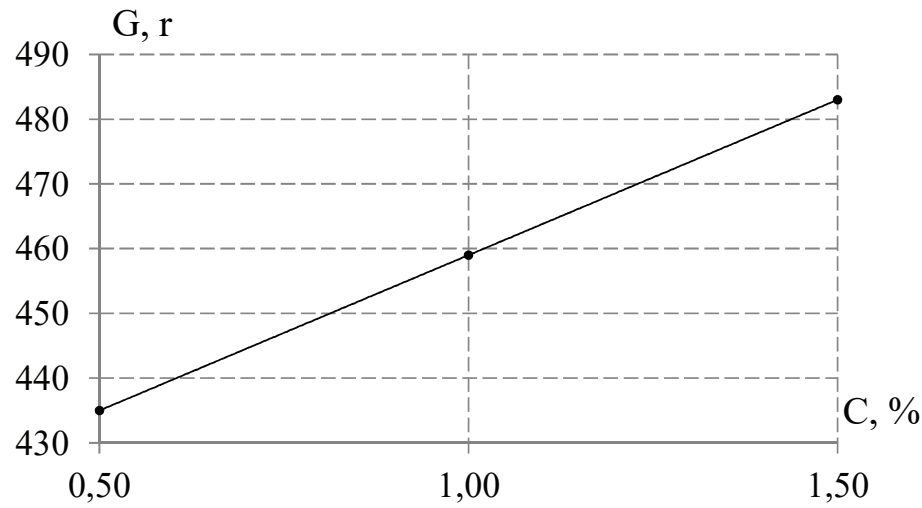

Fig. 4. Dependence of the strength of MS-2 gels

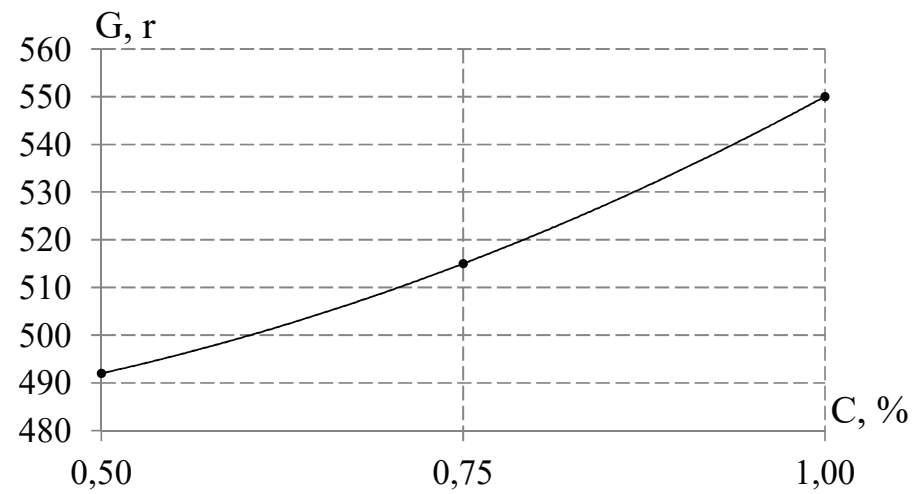

Fig. 5. Dependence of the strength of MS-3 gels

The stability of MS during storage was studied. It has been determined, that within 10 days for MS-1, MS-3 moisture is completely absent. For MS-2, MS-4 and for MS (control) there is a slight exfoliation of moisture (Fig. 7).

It has been found, that the combinations of locust bean polysaccharides $(0.5 \%)$ and xanthan gum $(0.75 \%)$ show the properties of moisture-binding ingredients, inhibit the processes of syneresis.

A mandatory component of cream is sugar, which can affect the strength of gels. It has been found, that sugar in the range of concentrations of 5.0...15.0\% increases the strength of gels based on experimental combinations of polysaccharides. 


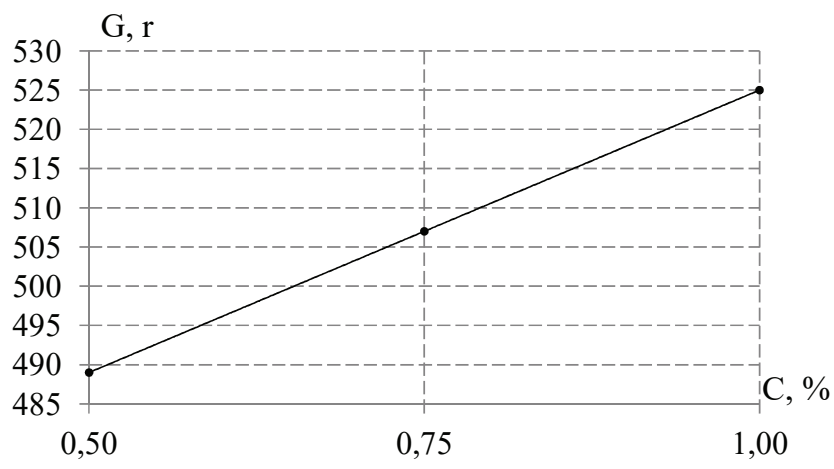

Fig. 6. Dependence of the strength of MS-4 gels

Table 2

The influence of the polysaccharide combination on the foaming ability of model systems

\begin{tabular}{cccc}
\hline Model system & Model system composition & FA, \% & $\begin{array}{c}\text { FS during } \\
\mathbf{4 0 \cdot 6 0} \mathbf{~ s} \%\end{array}$ \\
\hline MS-1 (control) & Cream - gelatin $(2.0 \%)$ & $555 \pm 3$ & $17.5 \pm 2.5$ \\
MS-2 & Cream $-\kappa$-carrageenan $(0.75 \%)-$ LBG $(0.5 \%)$ & $525 \pm 2$ & $10.5 \pm 1.5$ \\
MS-3 & Cream - agar $(1.5 \%)-$ LBG $(0.5 \%)$ & $515 \pm 2$ & $11.7 \pm 1.5$ \\
MS-4 & Cream - XG $(0.75 \%)-$ LBG $(0.5 \%)$ & $547 \pm 3$ & $4.5 \pm 1.0$ \\
MS-5 & Cream - LP $(0.25 \%)-\kappa$-carrageenan $(0.75 \%)$ & $551 \pm 3$ & $2.5 \pm 0.5$
\end{tabular}

Previous studies shown that combinations of polysaccharides using $k$-carrageenan and locust bean gum and xanthan gum and locust bean gum shown stable structural and mechanical properties at the maximum shear stress and during long-term storage. Combinations of polysaccharides with the following concentrations were selected for the study: MS-1 using $k$-carrageenan $(0.75 \%)$ and locust bean gum $(0.5 \%)$, in MS-2 using xanthan gum $(0.7 \%)$ and locust bean gum $(0.5 \%)$, gelatin at a concentration of $2.0 \%$ was used as a control (Fig. 8).

amount of liquid phase, detached at storage,

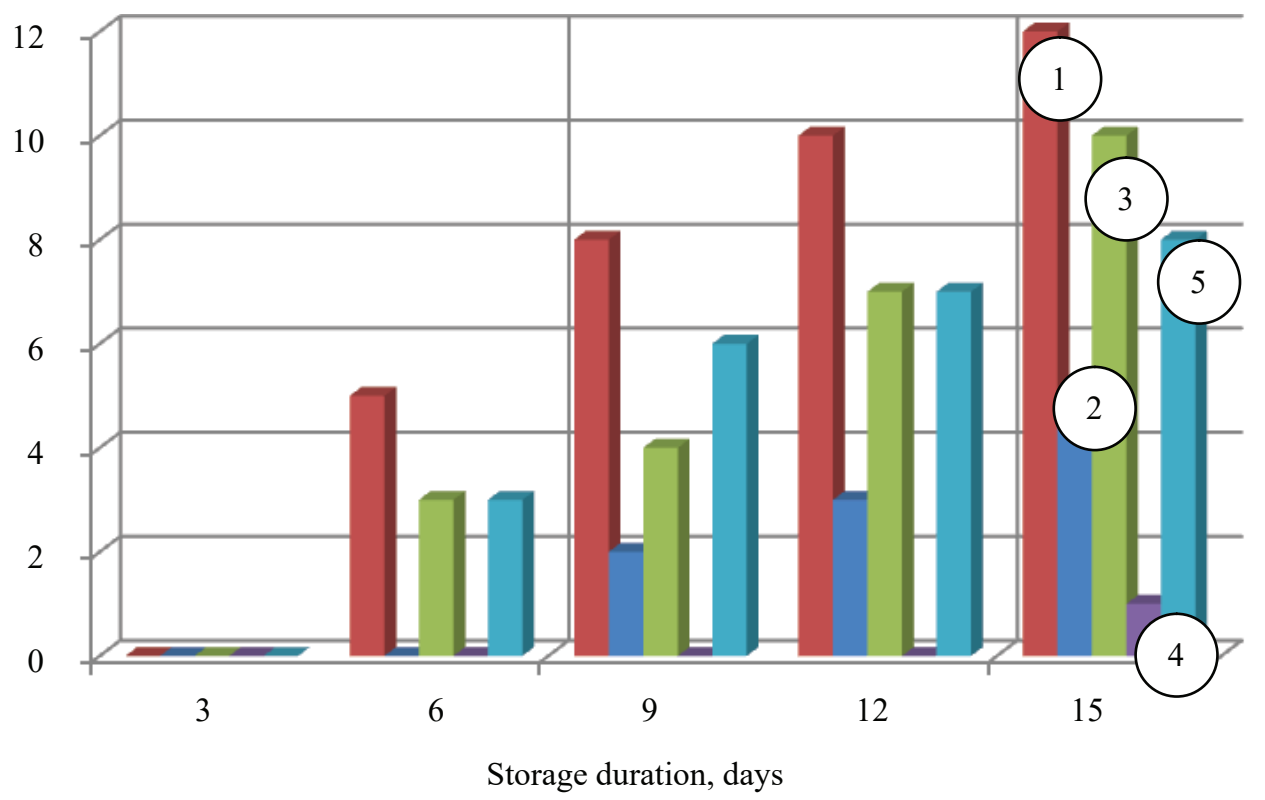

Fig. 7. Stability of model systems in the process of storage $\left(t_{\text {stor }}=4 \pm 2{ }^{\circ} \mathrm{C}\right)$ : 1 - MS (control); 2 - MS-1; 3 - MS-2; 4 - MS-3; 5 - MS-4; 6 - MS-5 
Thus, the introduction of sugar in a concentration of up to $15.0 \%$ helps to increase the strength of gels for all model systems. For MS-2 and MS 3, the strength increases by 2.5; 2.0 times. For MS (control), the strength of gels increases 1.7 times.

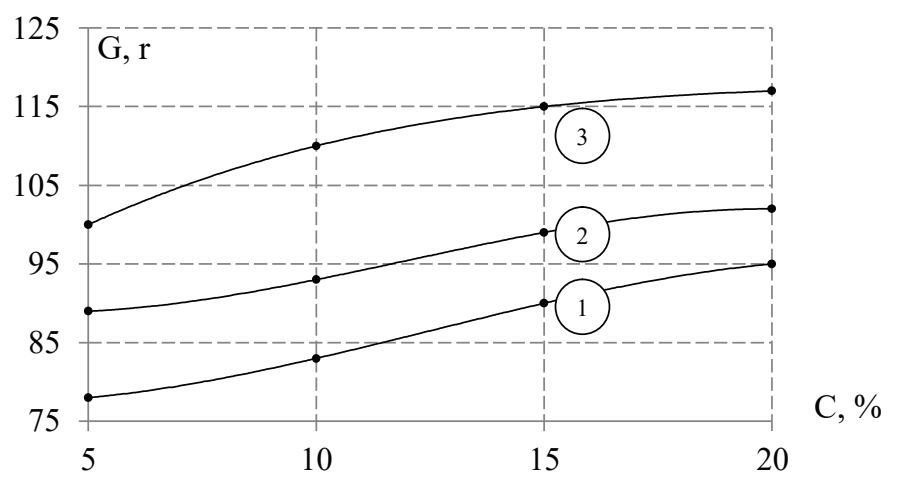

Fig. 8. Dependence of gel strength based on the combination of polysaccharides on white sugar content: 1 - MS-1 (control - gelatin $2.0 \%$ ); 2 - MS-2 ( $k$-carrageenan $-0.75 \% \div$ LBG $0.5 \%$ );

$$
3 \text { - MS-3 (XG }-0.7 \% \div \text { LBG } 0.5 \%)
$$

Thus, the experimental data and their analysis allowed to develop the technology of the stabilization system "XG - LBG" (Fig. 9).

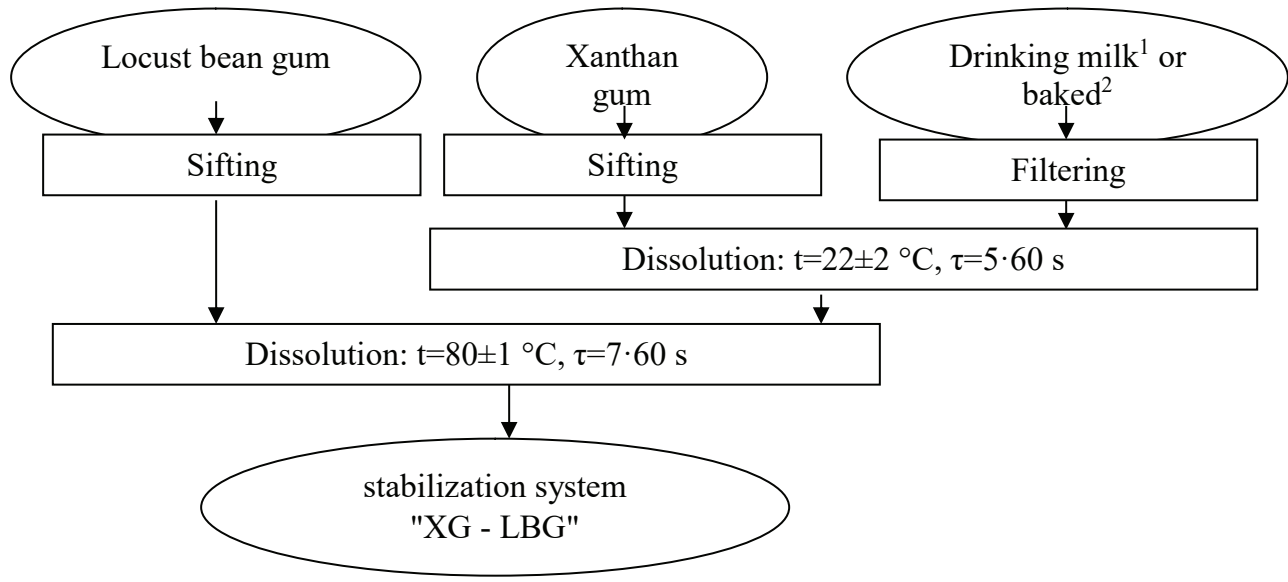

Fig. 9. The subsystem for the production of semi-finished products $(\mathrm{S} / \mathrm{p})$ «Stabilization system «Xanthan gum - locust bean gum»»»: 1 - drinking milk is used for cream «Forest berry»; 2 - baked milk is used for Latte cream

To expand the range of creams, fruit and berry puree "Wild berries", the active acidity $(\mathrm{pH})$ of which is 4.0, is used. The composition of fruit and berry puree includes: fresh blackberries, cranberries, strawberries, white sugar. The puree has already undergone heat treatment (pasteurization), so it can be added before the introduction of hydrocolloids.

Based on the study of the properties of combinations of polysaccharides, the expediency of using the combination "Xanthan gum $(0.75 \%$ - locust bean gum $(0.5 \%)$ " was established $)$. The optimal sugar content for cream creams is their concentration from $10 \%$ to $20 \%$.

On the basis of the conducted researches, cream "Forest berry", "Latte" was developed. Table 3 summarizes the results of organoleptic evaluation of the developed creams. The appearance of the developed creams is shown in Fig. 10.

One of the limitations in the technology of cream production is the difficulty of purchasing food additives (thickeners), which must comply not only with regulatory documentation, but also 
have the necessary technological properties. In the restaurant industry it is very difficult to determine the structural and mechanical properties of thickeners, and advertising information is not always reliable. Another limitation is that thickeners are mostly carrageenan, gum, xanthan, not domestic raw materials, and their cost is inflated.

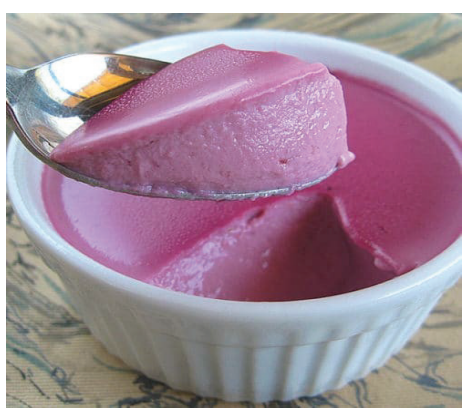

$a$

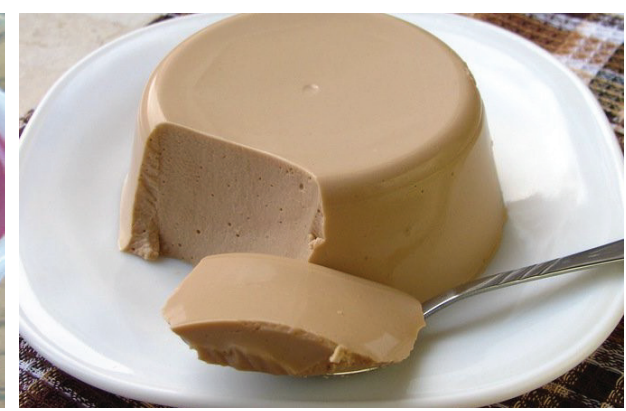

$b$

Fig.10. Photos of the developed creams: $a$ - cream "Forest berry"; $b$ - cream "Latte"

Table 3

The organoleptic evaluation of creams "Forest berry", "Latte"

\begin{tabular}{|c|c|c|}
\hline \multirow{2}{*}{$\begin{array}{l}\text { Parameter } \\
\text { name }\end{array}$} & \multicolumn{2}{|c|}{ Cream characteristic } \\
\hline & «Fruit berry» & «Latte» \\
\hline Outlook & \multicolumn{2}{|c|}{ Homogeneous product has a strict shape, no foreign inclusions, no signs of moisture, the surface is smooth } \\
\hline Consistence & \multicolumn{2}{|c|}{ Creamy with a characteristic chip, viscous-plastic, homogeneous without foreign inclusions } \\
\hline Color & $\begin{array}{l}\text { Natural, harmonious, saturated, from light purple to } \\
\text { pink, homogeneous and uniform in all volume }\end{array}$ & $\begin{array}{l}\text { Natural, harmonious, saturated, inherent in the color of } \\
\text { coffee, homogeneous and uniform in all volume }\end{array}$ \\
\hline $\begin{array}{l}\text { Taste and } \\
\text { smell }\end{array}$ & $\begin{array}{l}\text { Balanced, natural, stable, pronounced, pure, milky, } \\
\text { sweet and sour, with a pronounced taste and smell of } \\
\text { wild berries, without extraneous taste and smell }\end{array}$ & $\begin{array}{l}\text { Balanced, natural, stable, pronounced, pure. Sweet, ten- } \\
\text { der, with a characteristic taste of coffee and baked milk. } \\
\text { Without extraneous taste and smell }\end{array}$ \\
\hline
\end{tabular}

Today, manufacturers are increasingly modifying the thickeners of polysaccharide nature, to a greater extent to create combined additives or stabilization systems from several types of hydrocolloids. This need is carried out in order to obtain dessert products with various functional and technological properties, such as the ability to freeze and thaw, interact with alcohols, the ability to form gels at low $\mathrm{pH}$ and others.

Hydrocolloids of polysaccharide nature are used in the areas of molecular cuisine that is currently developing today. Technological processes, such as spherification, espumization, gelling, etc., today do not do without the use of hydrocolloids, in particular ionotropic, which have not yet been fully studied.

\section{Conclusions}

The prospects of using functional-technological ingredients, which are used as components-thickeners of cream, have been established, and the basic principles of regulation and combination of additives of polysaccharide origin have been determined.

The regularities of changes in the structural and mechanical properties of the combination of polysaccharides: "k-carrageenan - LBG", "agar - LBG", "XG -LBG", "k-carrageenan - LP" under the influence of technological factors have been studied. The regularities of the influence of white sugar on the gelling ability of model systems have been established. It has been graphically stated, that with a sugar content of $10 \%$ to $20 \%$, the structure of the gels has a strong, elastic consistency. It has been determined, that the combination of polysaccharides "XG - LBG" will have stable indicators. 
The foaming ability and the maximun shear stress of the model systems with the combination "xanthan gum - locust bean gum" have been studied, the concentration of xanthan gum $0.75 \%$ and locust bean gum $0.75 \%$ has been determined, soft and plastic gels and foams are formed according to stable quality indicators.

To expand the range, a filler "Forest Berries" - $17.0 \%$ was introduced to "Forest Berry" cream; for "Latte" cream, drinking milk was replaced by baked milk - 37.0\%, infused instant coffee $-4.0 \%$ was introduced as a filler. The requirements for the quality of finished products according to organoleptic parameters have been determined.

\section{References}

[1] Qin, Y. (2018). Seaweed Hydrocolloids as Thickening, Gelling, and Emulsifying Agents in Functional Food Products. Bioactive Seaweeds for Food Applications, 135-152. doi: https://doi.org/10.1016/b978-0-12-813312-5.00007-8

[2] Awuchi, C. G., Twinomuhwezi, H., Igwe, V. S., Amagwula, I. O. (2020). Food Additives and Food Preservatives for Domestic and Industrial Food Applications. Journal of Animal Health, 2 (1), 1-16. Available at: https://www.iprjb.org/journals/index. php/JAH/article/view/1067

[3] Kalman, D. S. (2019). Versatile Use of Gelatin in Functional Food and Nutraceuticals. Extreme and Rare Sports, 311-318. doi: https://doi.org/10.1201/9781315108025-17

[4] Cherevko, A. I., Mihaylova, V. M. (Eds.) (2016). Enciklopediya pitaniya. Vol. 4. Pischevye dobavki. Kharkiv: Mir Knig, 645.

[5] Sokolov, A. Yu., Shishkina, D. I. (2018). Hydrocolloids and Fibers in Food Composites. Ekonomicheski effektivnye i ekologicheski chistye innovacionnye tehnologii: materialy Pyatoy Mezhdunarodnoy nauchno-prakticheskoy konferencii. Moscow, $35-41$.

[6] Shishkina, A. V. (2020). Pischevye gidrokolloidy: svoystva, primenenie v konditerskoy promyshlennosti. Rynok gidrokolloidov. Innovacionnye podhody v sovremennoy nauke, 19 (79), 78-83.

[7] Skryplonek, K., Henriques, M., Gomes, D., Viegas, J., Fonseca, C., Pereira, C. et. al. (2019). Characteristics of lactose-free frozen yogurt with $\kappa$-carrageenan and corn starch as stabilizers. Journal of Dairy Science, 102 (9), 7838-7848. doi: https://doi.org/ 10.3168/jds.2019-16556

[8] Sheidaei, Z., Sarmadi, B., Hosseini, S. M., Javanmardi, F., Khosravi-Darani, K., Mortazavian, A. M. (2020). Influence of $\kappa$-Carrageenan, Modified Starch and Inulin Addition on Rheological and Sensory Properties of Non-fat and Non-added Sugar Dairy Dessert. Current Nutrition \& Food Science, 16 (4), 462-469. doi: https://doi.org/10.2174/1573401315666190301152645

[9] Míšková, Z., Salek, R. N., Křenková, B., Kůrová, V., Němečková, I., Pachlová, V., Buňka, F. (2021). The effect of א- and ı-carrageenan concentrations on the viscoelastic and sensory properties of cream desserts during storage. LWT, 145, 111539. doi: https://doi.org/10.1016/j.lwt.2021.111539

[10] Cheraghian, H., Mehraban Sangatash, M., Karazhyan, R., Nazari, Z. (2020). Optimization of non- dairy dessert formulations based on pumpkin by Mixture Design. Food Science and Technology, 16 (97), 1-12. doi: https://doi.org/10.29252/fsct.16.97.1

[11] Nepovinnykh, N. V., Kliukina, O. N., Ptichkina, N. M., Bostan, A. (2019). Hydrogel based dessert of low calorie content. Food Hydrocolloids, 86, 184-192. doi: https://doi.org/10.1016/j.foodhyd.2018.03.036

[12] Horalchuk, A. B., Pyvovarov, P. P., Hrynchenko, O. O., Pohozhykh, M. I., Polevych, V. V., Hurskyi, P. V. (2006). Reolohichni metody doslidzhennia syrovyny i kharchovykh produktiv ta avtomatyzatsiya rozrakhunkiv reolohichnykh kharakterystyk. Kharkiv: KhDUKhT, 63.

[13] Gomez, L. P., Alvarez, C., Zhao, M., Tiwari, U., Curtin, J., Garcia-Vaquero, M., Tiwari, B. K. (2020). Innovative processing strategies and technologies to obtain hydrocolloids from macroalgae for food applications. Carbohydrate Polymers, 248, 116784. doi: https://doi.org/10.1016/j.carbpol.2020.116784

How to cite: Andrieieva, S., Dikhtyar, A., Grinchenko, O., Pyvovarov, Y., Kolesnikova, M., Omel'chenko, S., Kotlyar, O. (2021). Development of technology of creams using hydrocolloids. EUREKA: Life Sciences, 6, 34-42. doi: https://doi.org/10.21303/25045695.2021 .002187 